Article

\title{
A Distribution Static Compensator Using a CFNN-AMF Controller for Power Quality Improvement and DC-Link Voltage Regulation
}

\author{
Kuang-Hsiung Tan ${ }^{1, *(D)}$, Faa-Jeng Lin ${ }^{2}$ (D) , Chao-Yang Tsai ${ }^{2}$ and Yung-Ruei Chang ${ }^{3}$ \\ 1 Department of Electrical and Electronic Engineering, Chung Cheng Institute of Technology, \\ National Defense University, Taoyuan 335, Taiwan \\ 2 Department of Electrical Engineering, National Central University, Taoyuan 320, Taiwan; \\ linfj@ee.ncu.edu.tw (F.-J.L.); 105521078@cc.ncu.edu.tw (C.-Y.T.) \\ 3 Nuclear Instrumentation Division, Institute of Nuclear Energy Research, Taoyuan 335, Taiwan; \\ raymond@iner.gov.tw \\ * Correspondence: gstan@ndu.edu.tw; Tel.: +886-3-380-9991 (ext. 128)
}

Received: 16 July 2018; Accepted: 30 July 2018; Published: 1 August 2018

\begin{abstract}
A distribution static compensator (DSTATCOM) is proposed in this study to improve the power quality, which includes the total harmonic distortion (THD) of the grid current and power factor (PF), of a mini grid with nonlinear and linear inductive loads. Moreover, the DC-link voltage regulation control of the DSTATCOM is essential especially under load variation conditions. Therefore, to improve the power quality and keep the DC-link voltage of the DSTATCOM constant under the variation of nonlinear and linear loads effectively, the traditional proportional-integral (PI) controller is substituted with a new online trained compensatory fuzzy neural network with an asymmetric membership function (CFNN-AMF) controller. In the proposed CFNN-AMF, the compensatory parameter to integrate pessimistic and optimistic operations of fuzzy systems is embedded in the CFNN. Furthermore, the dimensions of the Gaussian membership functions are directly extended to AMFs for the optimization of the fuzzy rules and the upgrade of learning ability of the networks. In addition, the network structure and online learning algorithm of the proposed CFNN-AMF are introduced in detail. Finally, the effectiveness and feasibility of the DSTATCOM using the proposed CFNN-AMF controller to improve the power quality and maintain the constant DC-link voltage under the change of nonlinear and linear inductive loads have been demonstrated by some experimental results.
\end{abstract}

Keywords: distribution static compensator; power quality; total harmonic distortion; compensatory neural fuzzy network; asymmetric membership function

\section{Introduction}

Recently, due to the increasing demand for electricity, limited supply of fossil fuels and the threats of climate change, distributed renewable energy sources has been extensively integrated into the existing power grid, especially at the distribution level [1,2]. Moreover, the usage of nonlinear loads such as household equipment, fluorescent lighting, solid-state power conversion devices and battery chargers is increasing day by day. Owing to the presence of these nonlinear loads, harmonics will be generated in the power system and cause heating of the windings of the distributed generators, increasing power pollution [3,4]. The poor power quality seriously deteriorates the voltage and current unbalance in the distribution system, and causes the undesirable operation of equipment $[5,6]$. Hence, power quality improvement has become an important issue for electric utilities [7]. On the other hand, due to the rapid development in power electronic technologies, the power quality and the 
power factor $(\mathrm{PF})$ in the distribution system can be improved effectively by using a distribution static compensator (DSTATCOM). In general, the DSTATCOM is composed of an inverter, DC-link capacitor and output inductors, and can be regarded as another kind of active filter [6,8,9]. According to the different extraction of current components, the control schemes of the DSTATCOM can be classified into two categories: synchronous reference frame methods ( $d q$ methods) and instantaneous active power theory ( $p q$ theory) [10-12]. The $d q$ methods mainly operate in $d q 0$ synchronous reference frame and separate the fundamental and the harmonic components of the load currents through a low-pass or high-pass filter. Thus, the adoption of a phase-lock-loop (PLL) algorithm is necessarily to compute the electrical angle of the source voltages in $d q$ methods [12]. However, the major disadvantage of the $d q$ methods is that undesirable second order harmonics will be generated in the $d q$-axis current commands under unbalanced load conditions [13]. On the other hand, the $p q$ theory is implemented in $\alpha \beta$ stationary reference frame and based on the calculation of the instantaneous active and reactive power of the loads [10]. Compared with the $d q$ methods, the $p q$ theory can effectively reduce the computation time without using the PLL algorithm and transferring to $d q 0$ synchronous reference frame. Furthermore, several studies that adopt the DSTATCOM approach to improve the power quality have been proposed for industrial applications [1,8,14-16]. A photovoltaic fed DSTATCOM using an optimization technique for the power quality improvement was proposed in [1]. In [8], a DSTATCOM peak detection method was proposed for the compensation in a three-phase four-wire distribution system. A distributed generator system with a DSTATCOM using a composite observer based control technique to improve the power quality was proposed in [14]. In [15], a cascaded H-bridge multilevel inverter-based DSTATCOM was developed for reactive power compensation and load balancing under linear load and unbalanced load conditions. A DSTATCOM based on a five-level flying-capacitor converter for power quality improvement was provided in [16]. In addition, due to the presence of the switching loss, filter loss and load variation conditions, the apparent power flowing into or out of the DC-link capacitor of DSTATCOM will cause a serious DC-link voltage fluctuation and affect the performance of power quality compensation $[1,2,6]$. Therefore, the DC-link voltage regulation control of DSTATCOM plays an important part especially under the load variation conditions. However, a sluggish regulation of the DC-link voltage of DSTATCOM was obtained by a traditional proportional-integral (PI) controller $[4,11,17]$.

A compensatory fuzzy neural network (CFNN), which adds a compensatory parameter in a traditional fuzzy neural network (FNN), was proposed in [18] to dynamically optimize adaptive fuzzy operations and adaptively adjust fuzzy membership functions. The CFNN adopts the optimistic fuzzy neurons, pessimistic fuzzy neurons, and compensatory fuzzy neurons to make a superior decision for the situation between the best and the worst cases [18]. Moreover, the convergence speed of the CFNN using the compensatory learning algorithm is faster than that of the traditional learning algorithms [18]. Hence, several studies adopting CFNN have also been proposed [19,20]. In [19], a CFNN without normalization was proposed as a pattern recognition technique for intelligent detection of Doppler ultrasound waveforms of abnormal neonatal cerebral hemodynamics. Furthermore, a recurrent neural network integrated into the CFNN for prediction and identification was proposed in [20]. On the other hand, the dimensions of the standard Gaussian membership functions (MFs) adopted in traditional fuzzy neural systems can be extended in asymmetric MFs (AMFs). Owing to the AMFs, the number of fuzzy rules can be optimized and the learning ability of the networks can be upgraded. Therefore, the AMFs have been adopted to improve the control precisions and optimize the number of fuzzy rules in some researches [21,22]. Owing to the above advantages of both the CFNN and AMF, a compensatory fuzzy neural network with an asymmetric membership function (CFNN-AMF), is proposed in this study for the control of a DSTATCOM to improve the power quality and maintain constant DC-link voltage under load variation conditions.

In this study, a DSTATCOM using the $p q$ theory is proposed to reduce the total harmonic distortion (THD) of the grid current and improve the PF of a mini grid with nonlinear and linear inductive loads. Moreover, to improve the DC-link voltage regulation control characteristics of the DSTATCOM under 
nonlinear and linear inductive loads variation conditions, an online trained CFNN-AMF is proposed as a regulation controller to take the place of a traditional PI controller in the DSTATCOM. Furthermore, the online training algorithm for the proposed CFNN-AMF based on the backpropagation (BP) method is derived in detail. In addition, the intelligent CFNN-AMF controlled DSTATCOM for power quality improvement is implemented in a personal computer (PC)-based control computer via Matlab and Simulink. In this study, the operational theories of the DSTATCOM will be presented in Section 2. Then, the network structure and online learning algorithm of the proposed CFNN-AMF will be introduced in Section 3. In Section 4, the effectiveness and feasibility of the DSTATCOM using the proposed CFNN-AMF controller for the improvement of power quality and maintaining the constant DC-link voltage will be demonstrated with some experimental results. Finally, the conclusions will be given in Section 5.

\section{DSTATCOM}

The circuit architecture of a mini grid with DSTATCOM and nonlinear and linear inductive loads is shown in Figure 1. The DC-link capacitor $C_{d c}$ and output inductor $L_{o}$ of the DSTATCOM are $3360 \mu \mathrm{F}$ and $10 \mathrm{mH}$, respectively. Moreover, the mini grid is connected with the power grid via a Y-Y transformer. The line to line voltages $v_{a b}, v_{b c}, v_{c a}$ on the primary side of the transformer are $110 \mathrm{Vrms}$. The secondary side of the transformer are the line to line voltage of the power grid with $220 \mathrm{Vrms}$ and the three-phase voltages $v_{s a}, v_{s b}, v_{s c}$ are $180 \mathrm{~V}$. The nonlinear and linear inductive loads will result in three-phase harmonic currents and lagging PF, respectively. In other words, the nonlinear and linear inductive loads can cause poor power quality and seriously deteriorate the balance of three-phase voltages and currents of the the distribution system. Thus, the purpose of the DSTATCOM is to generate the output currents $i_{o a}, i_{o b}, i_{o c}$ and make the three-phase grid currents $i_{s a}, i_{s b}, i_{s c}$ be sinusoidal and effectively improve the lagging PF. Furthermore, the control block of DSTATCOM using the $p q$ theory for the power quality improvement is illustrated in Figure 2. First, the line to line voltages $v_{a b}, v_{b c}, v_{c a}$ on the primary side of the transformer shown in Figure 1 are detected and transferred to three-phase voltages $v_{a}, v_{b}, v_{c}$. Then, the three-phase voltages $v_{a}, v_{b}, v_{c}$ and the detected three-phase load currents $i_{L a}, i_{L b}, i_{L c}$ are transferred to $\alpha \beta$ stationary reference frame as follows for instantaneous power calculation:

$$
\begin{aligned}
& {\left[\begin{array}{c}
v_{\alpha} \\
v_{\beta} \\
v_{0}
\end{array}\right]=\sqrt{\frac{2}{3}}\left[\begin{array}{ccc}
1 & -\frac{1}{2} & -\frac{1}{2} \\
0 & \frac{\sqrt{3}}{2} & -\frac{\sqrt{3}}{2} \\
\frac{1}{\sqrt{2}} & \frac{1}{\sqrt{2}} & \frac{1}{\sqrt{2}}
\end{array}\right]\left[\begin{array}{c}
v_{a} \\
v_{b} \\
v_{c}
\end{array}\right]} \\
& {\left[\begin{array}{c}
i_{L \alpha} \\
i_{L \beta} \\
i_{L 0}
\end{array}\right]=\sqrt{\frac{2}{3}}\left[\begin{array}{ccc}
1 & -\frac{1}{2} & -\frac{1}{2} \\
0 & \frac{\sqrt{3}}{2} & -\frac{\sqrt{3}}{2} \\
\frac{1}{\sqrt{2}} & \frac{1}{\sqrt{2}} & \frac{1}{\sqrt{2}}
\end{array}\right]\left[\begin{array}{c}
i_{L a} \\
i_{L b} \\
i_{L c}
\end{array}\right]}
\end{aligned}
$$

where $v_{\alpha}, v_{\beta}$ and $v_{0}$ are the $\alpha, \beta$ and zero axis voltages, respectively; $i_{L \alpha}, i_{L \beta}$ and $i_{L 0}$ are the $\alpha, \beta$ and zero axis currents, respectively. Since the balanced three-phase three-wire system is adopted in this study, the zero axis components $v_{0}$ and $i_{L 0}$ can be neglected. Then, the instantaneous power of the loads can be computed in the following $[10,17]$ :

$$
\left[\begin{array}{l}
P_{L} \\
Q_{L}
\end{array}\right]=\left[\begin{array}{cc}
v_{\alpha} & v_{\beta} \\
-v_{\beta} & v_{\alpha}
\end{array}\right]\left[\begin{array}{c}
i_{L \alpha} \\
i_{L \beta}
\end{array}\right]
$$

where $P_{L}$ and $Q_{L}$ are the instantaneous active power and reactive power of the loads respectively. Both the instantaneous active power and reactive power consist of the continuous and alternating components as follows [10,12]:

$$
P_{L}=\bar{P}_{L}+\widetilde{P}_{L}
$$




$$
Q_{L}=\bar{Q}_{L}+\widetilde{Q}_{L}
$$

where $\bar{P}_{L}$ and $\bar{Q}_{L}$ are the continuous parts; $\widetilde{P}_{L}$ and $\widetilde{Q}_{L}$ are the alternating parts. The continuous parts are the product of the fundamentals of the voltage and current. The alternating terms represent the power related to the product of the harmonic components of the voltage and current [12]. Then, the continuous active power component $\bar{P}_{L}$ can be extracted via a low pass filter which the transfer function is given as follows:

$$
T(s)=\frac{k \omega^{2}}{s^{2}+2 \xi \omega s+\omega^{2}}
$$

where the gain $k=1$, cut-off frequency $\omega=50 \pi \mathrm{rad} / \mathrm{s}$ and damping ratio $\xi=0.7$. The minus alternating active power component $-\widetilde{P}_{L}$ can be obtained by subtracting instantaneous active power $P_{L}$ from the continuous active power component $\bar{P}_{L}$. In addition, due to the presence of the switching loss, filter loss and load variation, the apparent power flowing into or out of the DC-link capacitor of DSTATCOM will cause the fluctuation of DC-link voltage and affect the performance of compensation. Hence, in order to maintain the constant DC-link voltage of the DSTATCOM, the DC-link voltage command $V_{d c}^{*}$ is compared with the DC-link voltage $V_{d c}$ and the error is sent to a controller to generate the power loss $\bar{P}_{\text {loss }}$. Three different controllers PI, CFNN and CFNN-AMF are adopted for the comparison of the voltage regulation control performance. Afterward, the power loss $\bar{P}_{\text {loss }}$ combines with the minus alternating active power component $-\widetilde{P}_{L}$. Additionally, the reactive power $Q_{s}$ of power grid is computed and compared with the reactive power command $Q_{s}^{*}$. The reactive power error is sent to a PI controller to obtain a reactive power correction $Q_{s e}$ and integrated into the instantaneous reactive power $Q_{L}$ through 180 degree phase shift for the correction of power factor [17]. Hence, the $\alpha \beta$ axis control commands $i_{o \alpha}^{*}$ and $i_{o \beta}^{*}$ can be obtained by the following equation [10,17]:

$$
\left[\begin{array}{c}
i_{o \alpha}^{*} \\
i_{o \beta}^{*}
\end{array}\right]=\frac{1}{v_{\alpha}^{2}+v_{\beta}^{2}}\left[\begin{array}{cc}
v_{\alpha} & -v_{\beta} \\
v_{\beta} & v_{\alpha}
\end{array}\right]\left[\begin{array}{l}
-\widetilde{P}_{L}+\bar{P}_{\text {loss }} \\
-Q_{L}-Q_{s e}
\end{array}\right]
$$

The three current commands $i_{o a}^{*}, i_{o b}^{*}, i_{o c}^{*}$ are calculated through $\alpha \beta / a b c$ coordinate transformation as follows:

$$
\left[\begin{array}{c}
i_{o a}^{*} \\
i_{o b}^{*} \\
i_{o c}^{*}
\end{array}\right]=\sqrt{\frac{2}{3}}\left[\begin{array}{cc}
1 & 0 \\
-\frac{1}{2} & \frac{\sqrt{3}}{2} \\
-\frac{1}{2} & -\frac{\sqrt{3}}{2}
\end{array}\right]\left[\begin{array}{c}
i_{o \alpha}^{*} \\
i_{o \beta}^{*}
\end{array}\right]
$$

Finally, the pulse width modulation (PWM) switching signals are generated for power quality improvement and maintaining the constant DC-link voltage $V_{d c}$ of the DSTATCOM under the nonlinear and linear inductive loads.

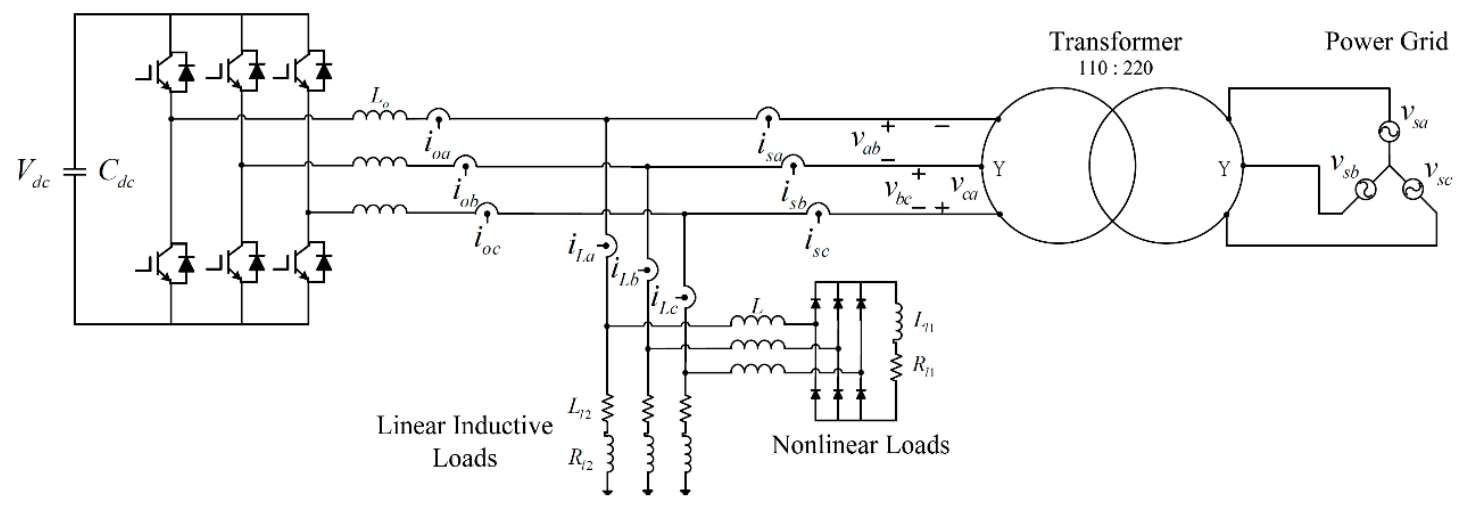

Figure 1. Circuit architecture of DSTATCOM with nonlinear and linear inductive loads. 


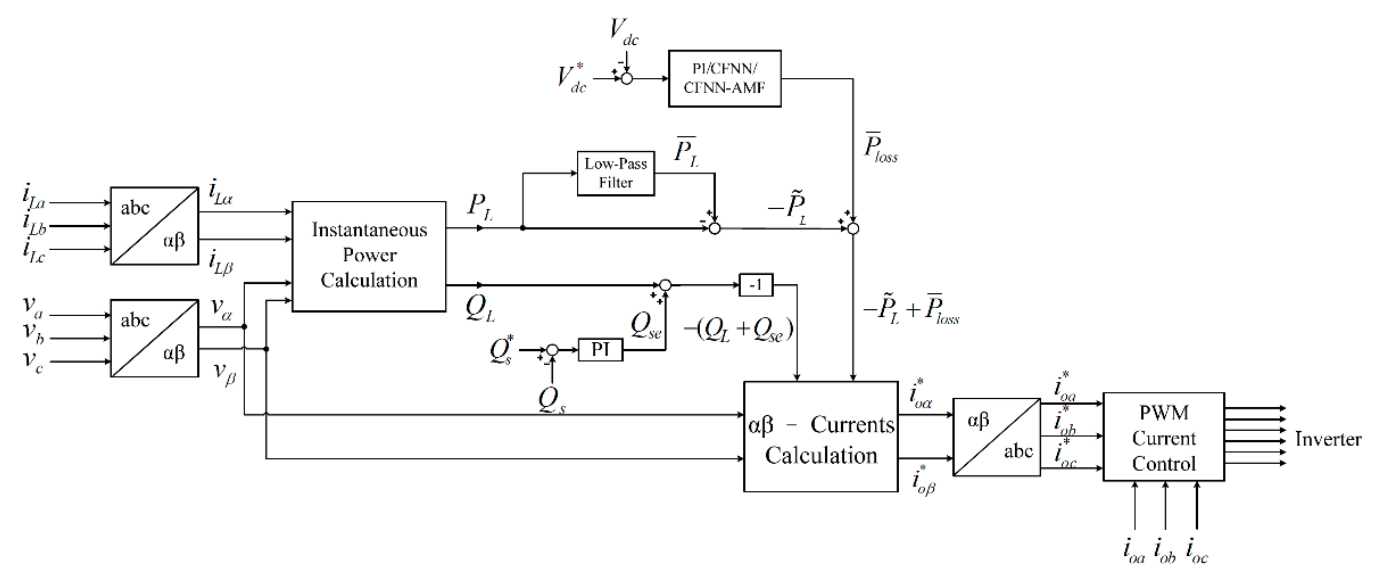

Figure 2. Control block of DSTATCOM.

\section{Intelligent CFNN-AMF Controller}

Since the DC-link voltage of the DSTATCOM will cause a serious fluctuation and affect the performance of compensation under the load variation conditions, the DC-link voltage regulation control is very important in the compensation of power quality. However, the sluggish regulation of the DC-link voltage of DSTATCOM was obtained by the PI controller due to the unsuitable parameters for different operating conditions and the disability in dealing with the system uncertainties. Hence, for the purpose of improving the power quality and DC-link voltage regulation control of the DSTATCOM under nonlinear and linear inductive loads variation conditions, the online trained CFNN-AMF is proposed as a regulation controller to take the place of the traditional PI controller in the DSTATCOM. The network structure and online learning algorithm using the BP of the proposed CFNN-AMF are represented in detail as follows:

\subsection{Network Architecture}

The network architecture of the proposed CFNN-AMF is shown in Figure 3a. The CFNN-AMF consists of the input layer (layer 1), membership layer (layer 2), rule and compensation layer (layer 3) and the output layer (layer 4). The compensatory characteristics are integrated into the rule layer to dynamically optimize adaptive fuzzy operations and adaptively adjust fuzzy membership functions. Thus, a superior decision can be made for the situation between the best and the worst cases [18]. The signal propagation of each layer is described in the following:

Input layer:

The relationship of the input and output in this layer is given as:

$$
\begin{gathered}
\operatorname{net}_{i}(N)=e_{i} \\
x_{i}(N)=f_{i}\left(\operatorname{net}_{i}(N)\right)=\operatorname{net}_{i}(N) \quad i=1,2
\end{gathered}
$$

where $x_{i}$ depicts the $i$ th input to the input layer; $N$ represents the $N$ th iteration. In this study, the inputs of the proposed CFMM-AMF are $e_{1}(N)=e$ and $e_{2}(N)=\dot{e}$, and the input variables are $e=V_{d c}^{*}-V_{d c}$ for the DC-link voltage regulation control of the DSTATCOM.

Membership layer:

The asymmetric Gaussian function as shown in Figure $3 \mathrm{~b}$ is adopted as the membership function in each node of the layer 2 to implement the fuzzification operation and to optimize the number of fuzzy rules. Moreover, the relations of each node are depicted in the following: 


$$
\begin{gathered}
\operatorname{net}_{j}(N)=\left\{\begin{array}{c}
-\frac{\left(x_{i}(N)-m_{j}(N)\right)^{2}}{\left(\sigma_{l j}(N)\right)^{2}},-\infty<x_{i}(N) \leq m_{j} \\
-\frac{\left(x_{i}(N)-m_{j}(N)\right)^{2}}{\left(\sigma_{r j}(N)\right)^{2}}, m_{j}<x_{i}(N) \leq \infty
\end{array}\right. \\
\mu_{j}(N)=f_{j}\left(\operatorname{net}_{j}(N)\right)=\exp \left(\text { net }_{j}(N)\right), \quad j=1,2, \ldots, 6
\end{gathered}
$$

where $m_{j}$ is the mean of the asymmetric Gaussian function; $\sigma_{l j}$ and $\sigma_{r j}$ are the left-hand-side and right-hand-side standard deviations of the asymmetric Gaussian function in the $j$ th term associated with the $i$ th input variable; $\mu_{j}(N)$ is the output of this layer. By empirical rules, the initial center of the mean $m_{j}$ is set to be -1 for $j=1,4,0$ for $j=2,5$ and 1 for $j=3,6$. The initial widths of the left-hand-side $\sigma_{l j}$ and right-hand-side $\sigma_{r j}$ standard deviations are both set to be 1 for $j=1,2,3,4,5,6$.

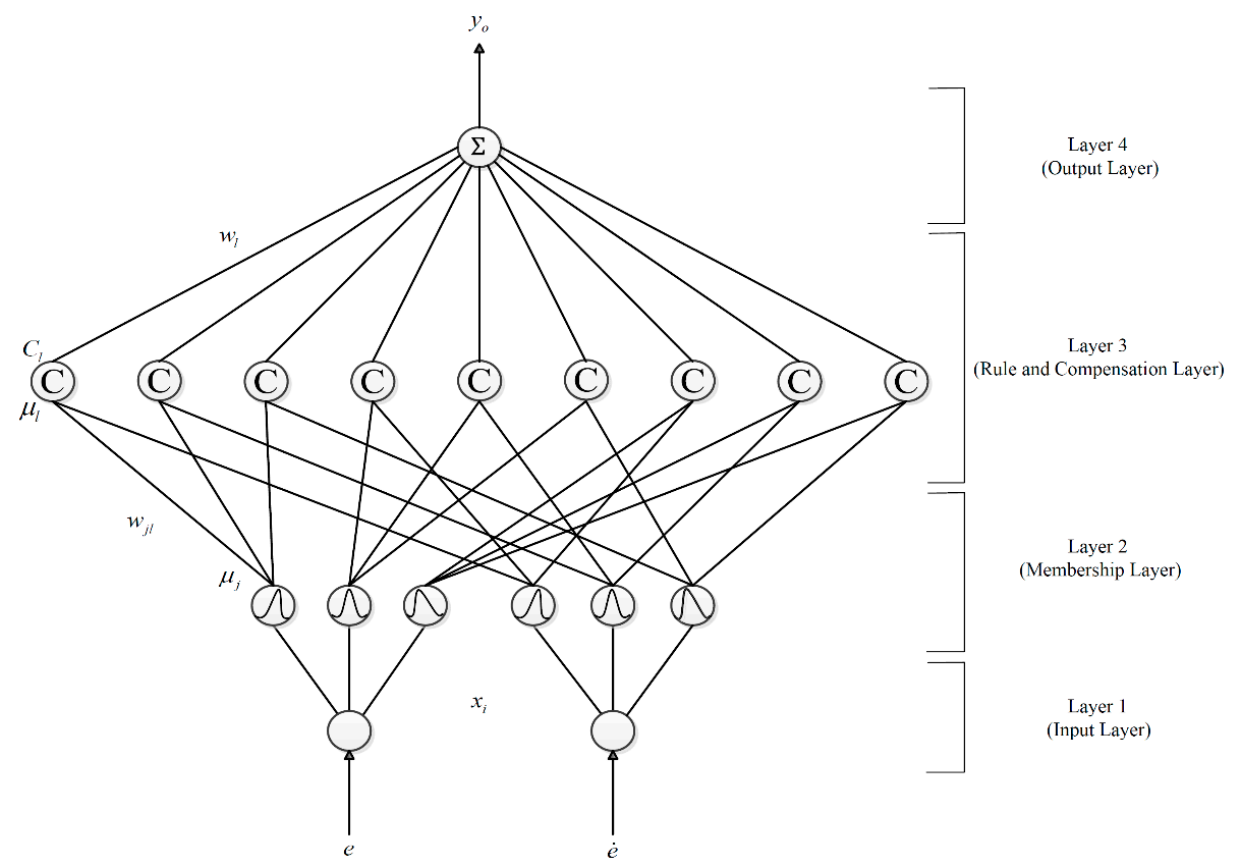

(a)

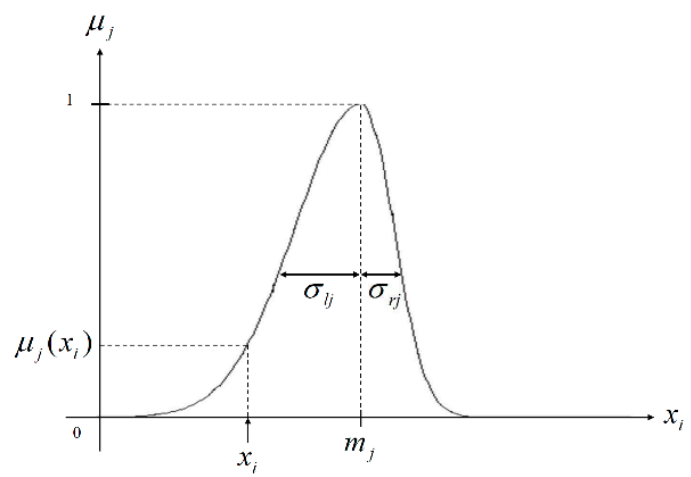

(b)

Figure 3. Network architecture of CFNN-AMF: (a) Network architecture; (b) Asymmetric Gaussian function.

Rule and compensation Layer:

In this layer, the nodes depict the precondition part of fuzzy logic rules. The compensatory parameters are integrated with this layer to perform IF-condition matching of fuzzy rules. As a result, the relationship of the input and output of the rule and compensation layer is described as follows: 


$$
\begin{gathered}
\mu_{l}=\prod_{j} w_{j l} \mu_{j} \\
\operatorname{net}_{l}(N)=\left(\mu_{l}\right)^{1-\gamma_{l}+\gamma_{l} / n}, \quad \gamma_{l}=[0,1], \quad n=2 \\
C_{l}(N)=f_{l}\left(\operatorname{net}_{l}(N)\right)=\operatorname{net}_{l}(N), \quad l=1,2, \ldots, 9
\end{gathered}
$$

where $\mu_{l}(N)$ is the input of rule layer; $w_{j l}$ is the connected weight between the membership layer and the rule and compensation layer which is set to be $1 ; \gamma_{l} \in[0,1]$ represents the compensatory degree; $C_{l}(N)$ is the $l$ th node output of the rule and compensation layer. If $\gamma_{l}$ is trained online, the compensatory operation becomes more adaptive. To ensure $\gamma_{l} \in[0,1]$, the compensatory degree $\gamma_{l}$ is defined as $\gamma_{l}=\frac{c_{l}^{2}}{\left(c_{l}^{2}+d_{l}^{2}\right)}$ [23], where parameters $c_{l}$ and $d_{l}$ will be trained real-time.

Layer 4 (output layer):

The node in this layer is expressed with $\sum$, which performs the summation operation. Therefore, the output of this layer can be described in the following:

$$
\begin{gathered}
\operatorname{net}_{o}(N)=\sum_{l} w_{l}(N) C_{l}(N) \\
y_{o}(N)=f_{o}\left(\operatorname{net}_{o}(N)\right)=\operatorname{net}_{o}(N), \quad o=1
\end{gathered}
$$

where $w_{l}$ is the connected weight between the rule and compensation layer and the output layer; $C_{l}(N)$ is the lth input of this layer; $y_{0}(N)$ is the output of the CFNN-AMF for the DC-link voltage regulation control in DSTATCOM.

\subsection{Online Learning Algorithm}

The online learning algorithm of the proposed CFNN-AMF is achieved by using the chain rule for the derivative of an error function with respect to a parameter of the network. Hence, for the purpose of deriving the online learning algorithm of the proposed CFNN-AMF, the error function $E$ is defined as:

$$
E(N)=\frac{1}{2}\left(V_{d c}{ }^{*}-V_{d c}\right)^{2}=\frac{1}{2} e^{2}
$$

The online learning parameters can be obtained by minimizing the error function $E$ and using the $\mathrm{BP}$ algorithm. The online learning algorithm is derived in the following:

Layer 4:

The propagated error term is calculated as:

$$
\delta_{o}^{4}=-\frac{\partial E}{\partial y_{o}(N)}=-\frac{\partial E}{\partial V_{d c}} \frac{\partial V_{d c}}{\partial y_{o}(N)}
$$

The connected weight $w_{l}$ is updated by the amount according to the chain rule:

$$
\Delta w_{l}=-\eta_{1} \frac{\partial E}{\partial w_{l}}=-\eta_{1} \frac{\partial E}{\partial y_{o}(N)} \frac{\partial y_{o}(N)}{\partial w_{l}}=\eta_{1} \delta_{o}^{4} C_{l}
$$

where $\eta_{1}$ is the learning rate. Hence, the updated value of the connected weight $w_{l}$ is given in the following:

$$
w_{l}(N+1)=w_{l}(N)+\Delta w_{l}
$$

Layer 3:

In layer 3, the propagated error term is computed in the following: 


$$
\delta_{o}^{3}=-\frac{\partial E}{\partial C_{l}(N)}=-\frac{\partial E}{\partial y_{o}(N)} \frac{\partial y_{o}(N)}{\partial C_{l}(N)}=\delta_{o}^{4} w_{l}
$$

Owing to the compensatory degree $\gamma_{l}=\frac{c_{l}{ }^{2}}{\left(c_{l}{ }^{2}+d_{l}{ }^{2}\right)}$, the parameters $c_{l}, d_{l}$ and $\gamma_{l}$ are updated by the following amounts:

$$
\begin{aligned}
\Delta c_{l} & =-\eta_{c} \frac{\partial E}{\partial c_{l}(N)}=-\eta_{c} \frac{\partial E}{\partial r_{l}(N)} \frac{\partial \gamma_{l}(N)}{\partial c_{l}(N)} \\
& =-\eta_{c} \frac{\partial E}{\partial \gamma_{l}(N)} \frac{2 c_{l}(N) d_{l}(N)^{2}}{\left(c_{l}(N)^{2}+d_{l}(N)^{2}\right)^{2}}=\eta_{c} \Delta \gamma_{l} \frac{2 c_{l}(N) d_{l}(N)^{2}}{\left(c_{l}(N)^{2}+d_{l}(N)^{2}\right)^{2}} \\
\Delta d_{l} & =-\eta_{d} \frac{\partial E}{\partial d_{l}(N)}=-\eta_{d} \frac{\partial E}{\partial r_{l}(N)} \frac{\partial \gamma_{l}(N)}{\partial d_{l}(N)} \\
& =-\eta_{d} \frac{\partial E}{\partial \gamma_{l}(N)} \frac{-2 c_{l}(N)^{2} d_{l}(N)}{\left(c_{l}(N)^{2}+d_{l}(N)^{2}\right)^{2}}=\eta_{d} \Delta \gamma_{l} \frac{-2 c_{l}(N)^{2} d_{l}(N)}{\left(c_{l}(N)^{2}+d_{l}(N)^{2}\right)^{2}} \\
\Delta \gamma_{l}=-\frac{\partial E}{\partial \gamma_{l}(N)} & =-\frac{\partial E}{\partial C_{l}(N)} \frac{\partial C_{l}(N)}{\partial \gamma_{l}(N)}=\delta_{o}^{3}\left(\frac{1}{n}-1\right)\left(\prod_{j} w_{j l} \mu_{j}\right)^{1-\gamma_{l}+\frac{\gamma_{l}}{n}} \ln \left(\prod_{j} w_{j l} \mu_{j}\right)
\end{aligned}
$$

where $\eta_{c}$ and $\eta_{d}$ are the learning rates. Thus, the updated values of the parameters $c_{l}, d_{l}$ and $\gamma_{l}$ are obtained as:

$$
\begin{gathered}
c_{l}(N+1)=c_{l}(N)+\Delta c_{l}=c_{l}(N)+\eta_{c}\left\{\frac{2 c_{l}(N) d_{l}^{2}(N)}{\left[c_{l}^{2}(N)+d_{l}^{2}(N)\right]^{2}}\right\} \Delta \gamma_{l} \\
d_{l}(N+1)=d_{l}(N)+\Delta d_{l}=d_{l}(N)-\eta_{d}\left\{\frac{2 c_{l}^{2}(N) d_{l}(N)}{\left[c_{l}^{2}(N)+d_{l}^{2}(N)\right]^{2}}\right\} \Delta \gamma_{l} \\
\gamma_{l}(N+1)=\frac{c_{l}^{2}(N+1)}{c_{l}^{2}(N+1)+d_{l}^{2}(N+1)}
\end{gathered}
$$

Layer 2:

In this layer, the error term needs to be computed and propagated in the following:

$$
\delta_{o}^{2}=-\frac{\partial E}{\partial n e t_{j}(N)}=-\frac{\partial E}{\partial C_{l}(N)} \frac{\partial C_{l}(N)}{\partial \mu_{j}(N)} \frac{\partial \mu_{l}(N)}{\partial n e t_{j}(N)}=\sum_{j} \delta_{o}^{3} \mu_{l}\left(1-\gamma_{l}+\frac{\gamma_{l}}{n}\right)\left(\prod_{j} w_{j l} \mu_{j}\right)^{-\gamma_{l}+\frac{\gamma_{l}}{n}}
$$

According to the chain rule, the update rules of the mean $m_{j}$, and left-hand-side $\sigma_{l j}$ and right-hand-side $\sigma_{r j}$ standard deviations of the asymmetric Gaussian function are calculated as follows:

$$
\begin{gathered}
\Delta m_{j}=-\eta_{2} \frac{\partial E}{\partial m_{j}}=-\eta_{2} \frac{\partial E}{\partial \mu_{j}(N)} \frac{\partial \mu_{j}(N)}{\partial m_{j}} \\
=\left\{\begin{array}{c}
2 \eta_{2} \delta_{o}^{2} \frac{\left(x_{i}(N)-m_{j}(N)\right)}{\left(\sigma_{l j}(N)\right)^{2}},-\infty<x_{i}(N) \leq m_{j} \\
2 \eta_{2} \delta_{0}^{2} \frac{\left(x_{i}(N)-m_{j}(N)\right)}{\left(\sigma_{r j}(N)\right)^{2}}, m_{j}<x_{i}(N) \leq \infty
\end{array}\right. \\
\Delta \sigma_{l j}=-\eta_{3} \frac{\partial E}{\partial \sigma_{l j}}=-\eta_{3} \frac{\partial E}{\partial \mu_{l j}(N)} \frac{\partial \mu_{l j}(N)}{\partial \sigma_{l j}}=2 \eta_{3} \delta_{o}^{2} \frac{\left(x_{i}-m_{j}\right)^{2}}{\left(\sigma_{l j}\right)^{3}} \\
\Delta \sigma_{r j}=-\eta_{4} \frac{\partial E}{\partial \sigma_{r j}}=-\eta_{4} \frac{\partial E}{\partial \mu_{r j}(N)} \frac{\partial \mu_{r j}(N)}{\partial \sigma_{r j}}=2 \eta_{4} \delta_{o}^{2} \frac{\left(x_{i}-m_{j}\right)^{2}}{\left(\sigma_{r j}\right)^{3}}
\end{gathered}
$$

where $\eta_{2}, \eta_{3}$ and $\eta_{4}$ are the learning rates of the mean and left-hand-side and right-hand-side standard deviations respectively. Then, the updated values of the parameters are given as follows: 


$$
\begin{aligned}
& m_{j}(N+1)=m_{j}(N)+\Delta m_{j} \\
& \sigma_{l j}(N+1)=\sigma_{l j}(N)+\Delta \sigma_{l j} \\
& \sigma_{r j}(N+1)=\sigma_{r j}(N)+\Delta \sigma_{r j}
\end{aligned}
$$

In general, the exact calculation of the Jacobian of the system, $\partial V_{d c} / \partial y_{o}(N)$ is difficult to be determined due to the unknown dynamics of the DSTATCOM. To overcome this problem, a delta adaptation law is adopted as follows:

$$
\delta_{o}^{4} \cong e+\dot{e}
$$

\section{Experimental Results}

In this study, the intelligent CFNN-AMF controlled DSTATCOM for power quality improvement and DC-link voltage regulation control under load variation conditions is implemented in a PC-based control computer via Matlab and Simulink with $0.2 \mathrm{~ms}$ sampling time. The block diagram of the DSTATCOM and the photos of the control system are illustrated in Figure 4a,b respectively. In Figure 4a, the line to line voltages $v_{a b}, v_{b c}, v_{c a}$, DC-link voltage $V_{d c}$, grid currents $i_{s a}, i_{s b}, i_{s c}$ and load currents $i_{L a}, i_{L b}, i_{L c}$ are detected via A/D converter. Then, by using the control algorithms, which include the instantaneous power calculation, harmonics detection, DC-link voltage regulation control and intelligent CFNN-AMF controller, the current commands $i_{o a}^{*}, i_{o b}^{*}, i_{o c}^{*}$ are generated and sent to the current controlled PWM module through D/A converter to generate the PWM signals for the inverter. The purpose of the DSTATCOM is to generate the output currents $i_{o a}, i_{o b}, i_{o c}$ to make the three-phase grid currents $i_{s a}, i_{s b}, i_{s c}$ be sinusoidal and improve the PF effectively. Moreover, a bridge rectifier composed of six diodes with a resistor $R_{l 1}$ and an inductor $L_{l 1}$ is considered as the nonlinear load.

Three different loads are designed in the following: (1) nonlinear load 1 is composed of $L_{l 1}=1 \mathrm{mH}, R_{l 1}=100 \Omega$; (2) nonlinear load 2 is composed of $L_{l 1}=1 \mathrm{mH}, R_{l 1}=75 \Omega$; (3) nonlinear load 3 is composed of $L_{l 1}=1 \mathrm{mH}, R_{l 1}=50 \Omega$. The inductor $L$ is $6 \mathrm{mH}$. Furthermore, a resistor $R_{l 2}$ and an inductor $L_{l 2}$ are connected in series to regard as the linear inductive loads. Three different loads are designed as follows: (1) linear inductive load 1 is composed of $R_{l 2}=25 \Omega, L_{l 2}=30 \mathrm{mH}$; (2) linear inductive load 2 is composed of $R_{l 2}=25 \Omega, L_{l 2}=40 \mathrm{mH}$; (3) linear inductive load 3 is composed of $R_{l 2}=25 \Omega, L_{l 2}=50 \mathrm{mH}$. In addition, the DC-link voltage command $V_{d c}^{*}$ is set to be $250 \mathrm{~V}$. The reactive power command $Q_{s}^{*}$ is set to be 0 Var for power factor correction. Additionally, the experimental results using PI, CFNN-AMF and the proposed CFNN-AMF controlled DSTATCOMs are provided for the comparison of control performance.

The experimental results without using the DSTATCOM and the experimental results using PI, CFNN and the proposed CFNN-AMF controlled DSTATCOMs at the nonlinear load 3 are provided to verify the effectiveness of reducing the THD of the grid current as shown in Figure 5. The responses of the grid current $i_{s a}$, output current $i_{o a}$ and load current $i_{L a}$ without using the DSTATCOM are illustrated in Figure $5 \mathrm{a}$. In Figure $5 \mathrm{a}$, the grid current $i_{s a}$ fluctuates seriously owing to the nonlinear load 3 and the absence of DSTATCOM. And the THD of the grid current $i_{s a}$ is $24 \%$. Moreover, the responses of the DC-link voltage $V_{d c}$ grid current $i_{s a}$, output current $i_{o a}$ and load current $i_{L a}$ using PI, CFNN and the proposed CFNN-AMF controlled DSTATCOMs at the nonlinear load 3 are provided in Figure $5 \mathrm{~b}-\mathrm{d}$, respectively. From the experimental results shown in Figure $5 \mathrm{~b}-\mathrm{d}$, the grid current $i_{s a}$ can be compensated to be sinusoidal and the THDs of the grid current can be reduced to be $4.54 \%$, $4.28 \%$ and $4.17 \%$, respectively, to meet the IEEE 519 regulation (5\%) [24]. Furthermore, the THDs of grid current without using DSTATCOM and using PI, CFNN and the proposed CFNN-AMF controlled DSTATCOMs at the nonlinear loads 1-3 are provided in Table 1. From Table 1 and the experimental results shown in Figure 5, since the PI controller is not robust in coping with the system uncertainties, the current THD of the PI controlled DSTATCOM is the worst at different nonlinear loads. On the other hand, due to online learning capacity and the AMFs of the proposed CFNN-AMF controller, the number of fuzzy rules can be optimized and the learning ability of the networks can be upgraded. 
Thus, the current THDs of the proposed CFNN-AMF controlled DSTATCOM are smaller than the CFNN controlled DSTATCOM.

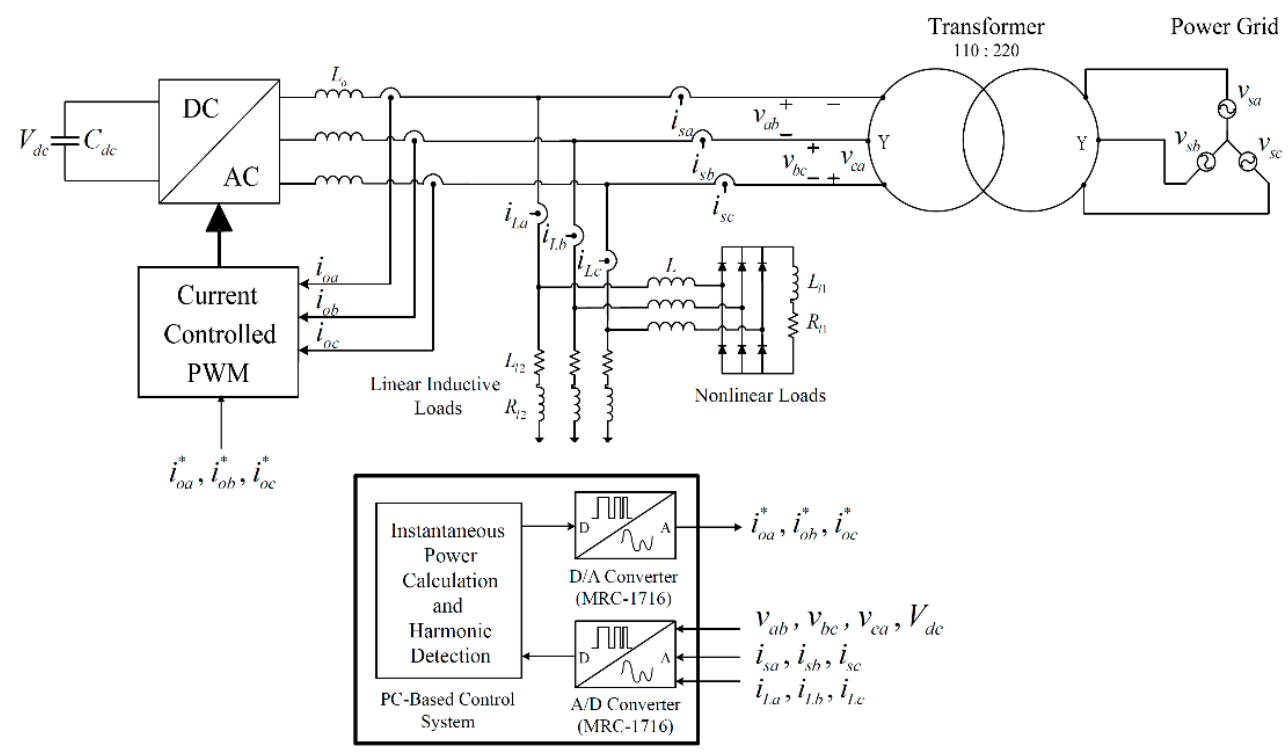

(a)

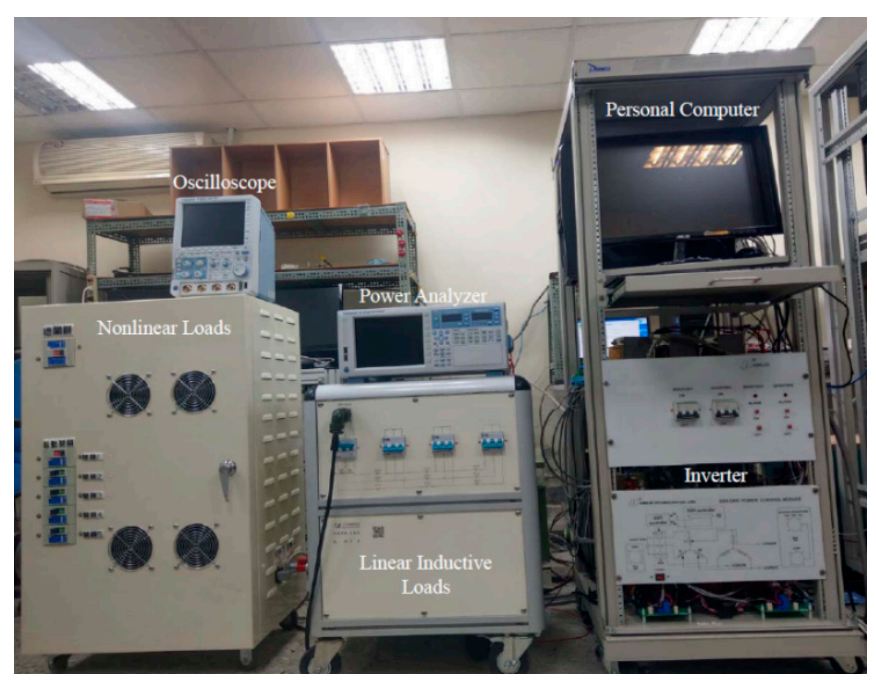

(b)

Figure 4. PC-based DSTATCOM: (a) Block diagram of DSTATCOM; (b) Photo of control platform, loads and inverter.

Table 1. Current THDs without using DSTATCOM and using DSTATCOM with different controllers at nonlinear loads $1-3$.

\begin{tabular}{ccccc}
\hline \multirow{2}{*}{$\begin{array}{c}\text { Active } \\
\text { Compensation }\end{array}$} & DC-Link & \multicolumn{3}{c}{ THD of Phase-A Grid Current (\%) } \\
\cline { 3 - 5 } & Controllers & Nonlinear Load 1 & Nonlinear Load 2 & Nonlinear Load 3 \\
\hline Without DSTATCOM & - & 26 & 25.27 & 24 \\
DSTATCOM & PI & 4.83 & 4.61 & 4.54 \\
DSTATCOM & CFNN & 4.56 & 4.43 & 4.28 \\
DSTATCOM & CFNN-AMF & 4.45 & 4.22 & 4.17 \\
\hline
\end{tabular}




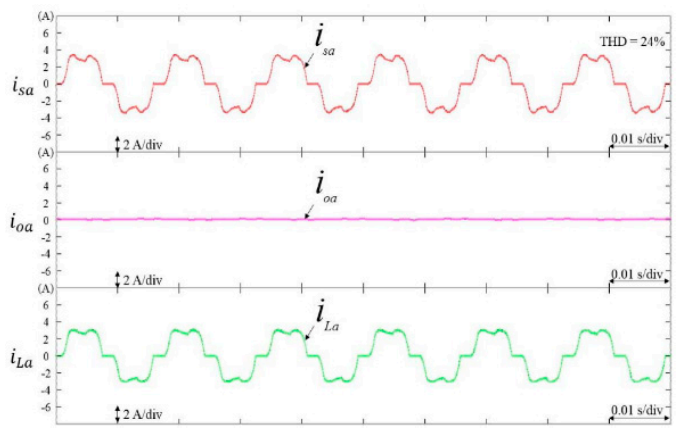

(a)

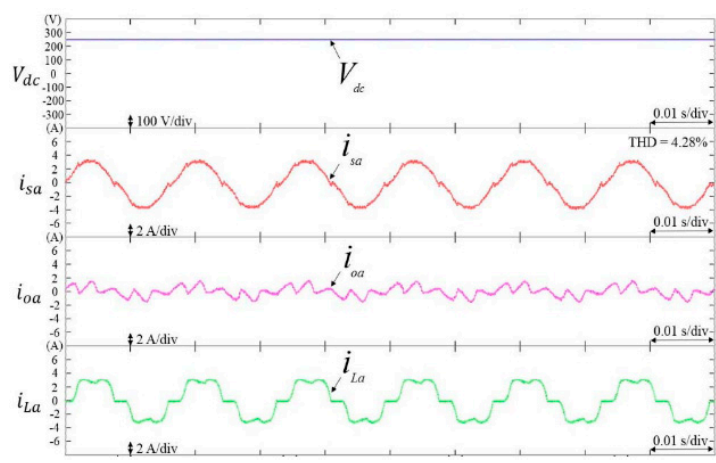

(c)

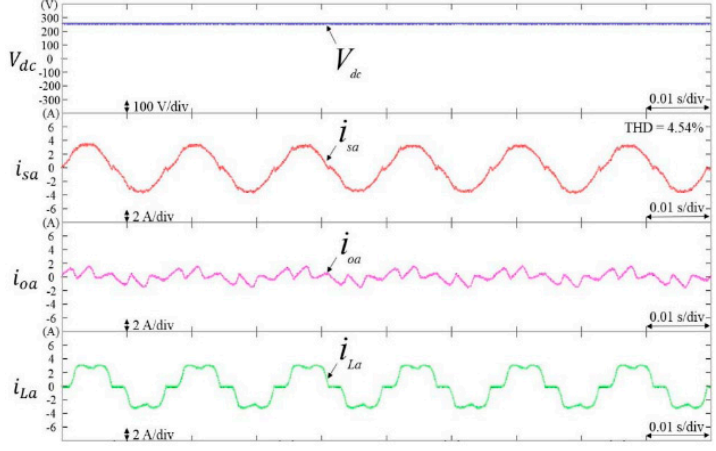

(b)

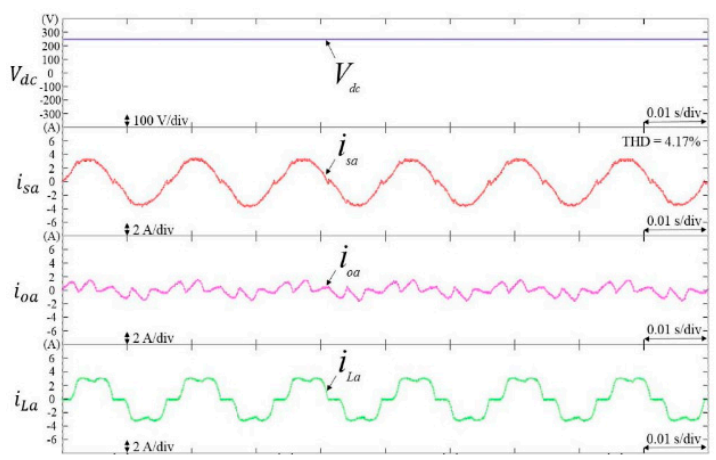

(d)

Figure 5. Experimental results at nonlinear load 3: (a) Without using DSTATCOM; (b) Using PI controlled DSTATCOM; (c) Using CFNN controlled DSTATCOM; (d) Using proposed CFNN-AMF controlled DSTATCOM.

To show the effectiveness of improving the $\mathrm{PF}$, the experimental results without using the DSTATCOM and the experimental results using PI, CFNN and the proposed CFNN-AMF controlled DSTATCOMs at the linear inductive load 3 are represented in Figure 6. The responses of the grid current $i_{s a}$ and phase voltage $v_{a}$ without using the DSTATCOM is provided in Figure 6a with lagging PF 0.8. Moreover, the responses of the grid current $i_{s a}$, phase voltage $v_{a}$ and DC-link voltage $V_{d c}$ using PI, CFNN and the proposed CFNN-AMF controlled DSTATCOMs at the linear inductive load 3 are illustrated in Figure $6 \mathrm{~b}-\mathrm{d}$ respectively. Since the DSTATCOM possesses the ability to improve the PF effectively, the PFs of the PI, CFNN and the proposed CFNN-AMF controlled DSTATCOMs can be improved to be $0.996,0.998$ and 0.998 , respectively. Furthermore, the PFs without using DSTATCOM and using PI, CFNN and the proposed CFNN-AMF controlled DSTATCOMs at the linear inductive loads $1-3$ is presented in Table 2.

Table 2. PFs without using DSTATCOM and using DSTATCOM with different controllers at linear inductive loads $1-3$.

\begin{tabular}{ccccc}
\hline \multirow{2}{*}{$\begin{array}{c}\text { Active } \\
\text { Compensation }\end{array}$} & \multirow{2}{*}{$\begin{array}{c}\text { DC-Link } \\
\text { Controllers }\end{array}$} & \multicolumn{3}{c}{ Power Factor (PF) } \\
\cline { 3 - 5 } & & Linear Inductive Load 1 & Linear Inductive Load 2 & Linear Inductive Load 3 \\
\hline Without DSTATCOM & - & 0.912 & 0.856 & 0.8 \\
DSTATCOM & PI & 0.997 & 0.997 & 0.996 \\
DSTATCOM & CFNN & 0.998 & 0.998 & 0.998 \\
DSTATCOM & CFNN-AMF & 0.999 & 0.998 & 0.998 \\
\hline
\end{tabular}




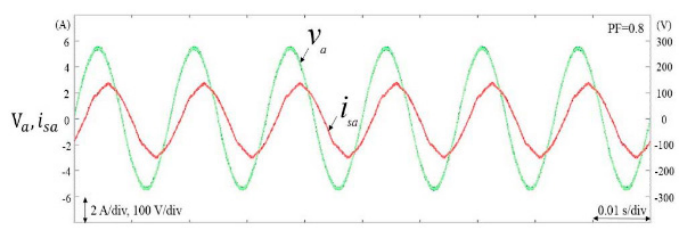

(a)

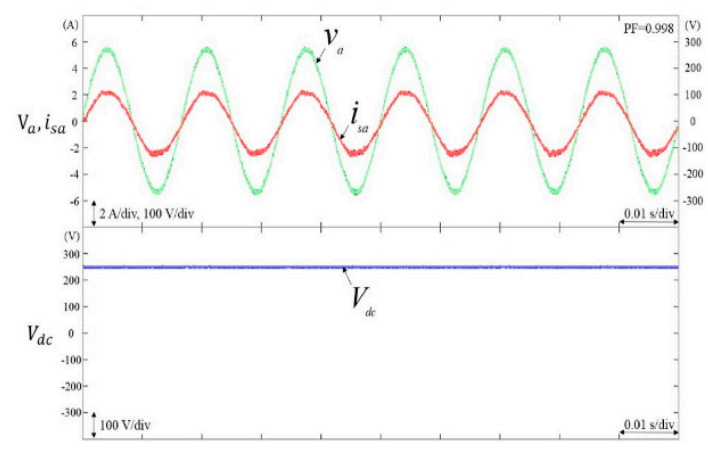

(c)

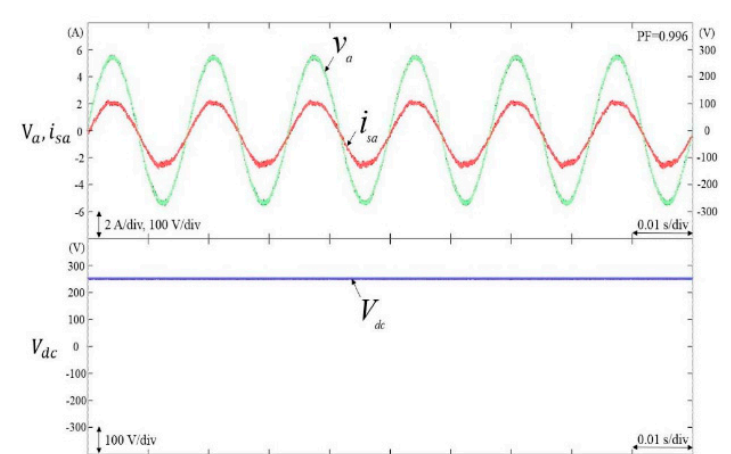

(b)

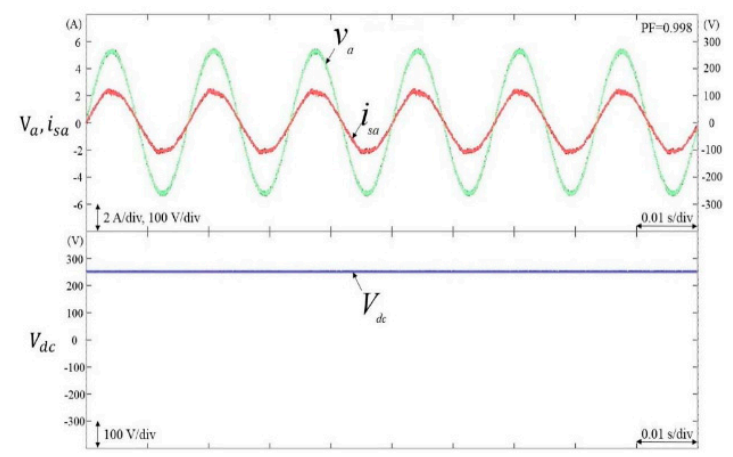

(d)

Figure 6. Experimental results at linear inductive load 3: (a) Without using DSTATCOM; (b) Using PI controlled DSTATCOM; (c) Using CFNN controlled DSTATCOM; (d) Using proposed CFNN-AMF controlled DSTATCOM.

From Table 2, the PFs of the CFNN and the proposed CFNN-AMF controlled DSTATCOMs are better than the PI controlled DSTATCOM. Though the PFs of the CFNN and the proposed CFNN-AMF controlled DSTATCOMs are the same at the linear inductive loads 2-3, the proposed CFNN-AMF controlled DSTATCOM is still superior than the CFNN controlled DSTATCOM at the linear inductive load 1 due to the merit of the CFNN-AMF controller.

For the purpose of proving the validity of the DC-link voltage regulation control of the DSTATCOM under load variation situation, two scenarios are designed in the following: (1) case 1 is composed of linear inductive load 1 with nonlinear load changing from load 1 to load 3 at $1 \mathrm{~s}$; (2) case 2 is composed of nonlinear load 1 with linear inductive load changing from load 1 to load 3 at $1 \mathrm{~s}$. The experimental results at case 1 are provided in Figure 7 . The responses of DC-link voltage $V_{d c}$ and grid current $i_{s a}$ using PI, CFNN and the proposed CFNN-AMF controlled DSTATCOMs at case 1 are illustrated in Figure 7a-c, respectively. From the experimental results shown in Figure 7, due to the disability of PI controller in coping with the system uncertainties, a sluggish DC-link voltage regulation control response is obtained as shown in Figure 7a. Moreover, since the proposed CFNN-AMF controller possesses the optimized fuzzy rules ability of the AMF, the DC-link voltage regulation control of the proposed CFNN-AMF controlled DSTATCOM is superior to the CFNN controlled DSTATCOM. Furthermore, the response time of the DC-link voltage and the regulation voltage error of the PI, CFNN and CFNN-AMF controlled DSTATCOMs at case 1 are presented in Table 3. According to Table 3, the proposed CFNN-AMF controlled DSTATCOM owns quick response time and smaller regulation voltage error during the load change. Therefore, outstanding DC-link voltage regulation effect can be achieved by using the proposed CFNN-AMF controlled DSTATCOM. In addition, to verify the online learning ability of the proposed CFNN-AMF, the waveforms of $w_{3}$, $\gamma_{3}, m_{3}, \sigma_{l 3}$ and $\sigma_{r 3}$ of the proposed CFNN-AMF for the DC-link voltage regulation control at case 1 as 
shown in Figure 7c are provided in Figure 8a-e, respectively. From the responses shown in Figure 8, the effectiveness of the online learning algorithm based on $\mathrm{BP}$, the compensatory degree and the developed AMF property in the proposed CFNN-AMF controller are achieved. Additionally, the experimental results using the PI, CFNN and proposed CFNN-AMF controlled DSTATCOMs at case 2 are provided in Figure 9a-c. The response time of the DC-link voltage and the regulation voltage error of the PI, CFNN and proposed CFNN-AMF controlled DSTATCOMs at case 2 are listed in Table 4. From the experimental results shown in Figure 9 and Table 4, the proposed CFNN-AMF controlled DSTATCOM still possesses the best DC-link voltage regulation control characteristics.

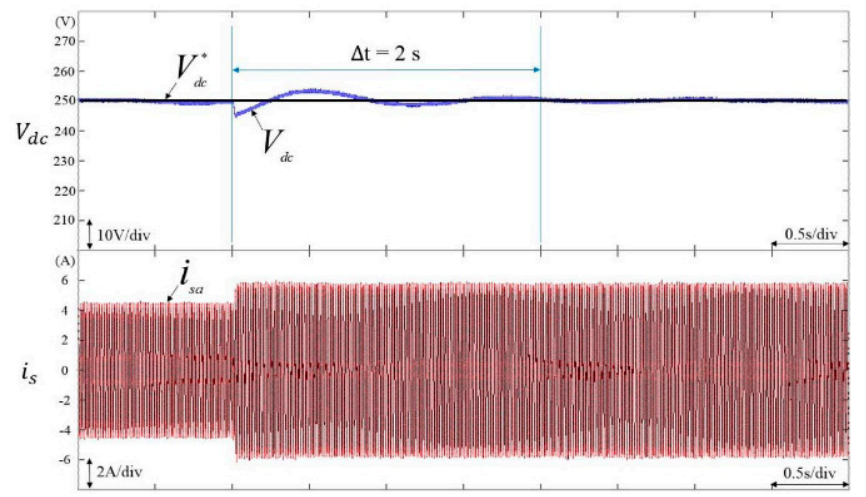

(a)

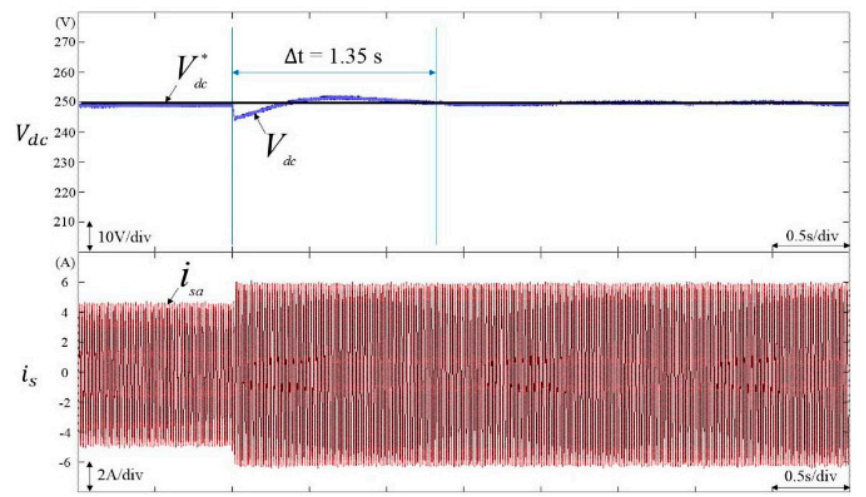

(b)

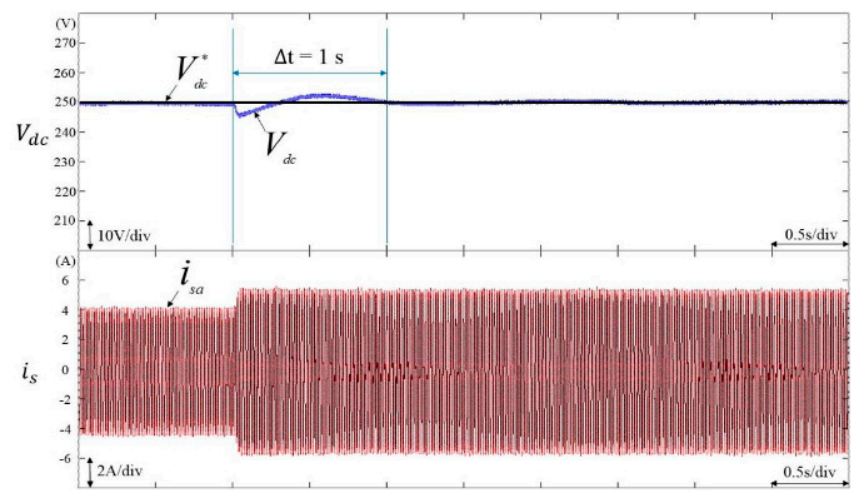

(c)

Figure 7. Experimental results at case 1: (a) Responses of DC-link voltage $V_{d c}$ and grid current $i_{s a}$ using PI controlled DSTATCOM; (b) Responses of DC-link voltage $V_{d c}$ and grid current $i_{s a}$ using CFNN controlled DSTATCOM; (c) Responses of DC-link voltage $V_{d c}$ and grid current $i_{s a}$ using proposed CFNN-AMF controlled DSTATCOM. 
Table 3. Response time of DC-link voltage and regulation voltage error for different controllers at case 1 .

\begin{tabular}{cccc}
\hline \multirow{2}{*}{$\begin{array}{c}\text { Case } \\
\text { Condition }\end{array}$} & \multirow{2}{*}{ DC-Link } & Response Time (s) & Overshoot to Undershoot (V) \\
\cline { 3 - 4 } & Controllers & Nonlinear Load 1 $\rightarrow$ Nonlinear Load 3 & Nonlinear Load 1 $\rightarrow$ Nonlinear Load 3 \\
\hline \multirow{2}{*}{ Case 1} & PI & 2 & 9.6 \\
& CFNN & 1.35 & 8.3 \\
& CFNN-AMF & 1 & 7.9 \\
\hline
\end{tabular}

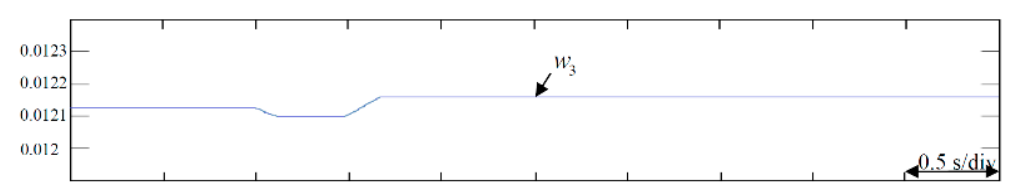

(a)

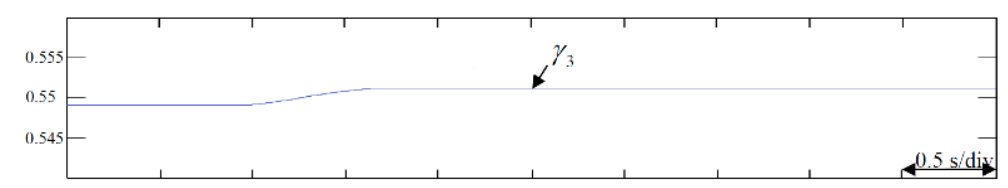

(b)

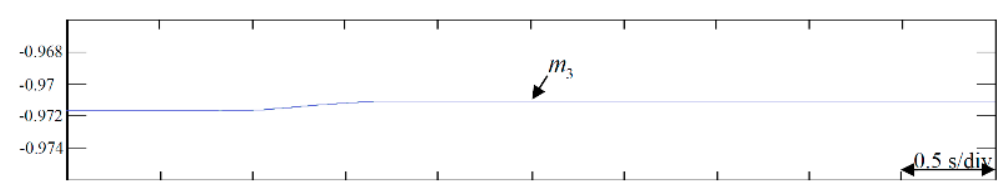

(c)

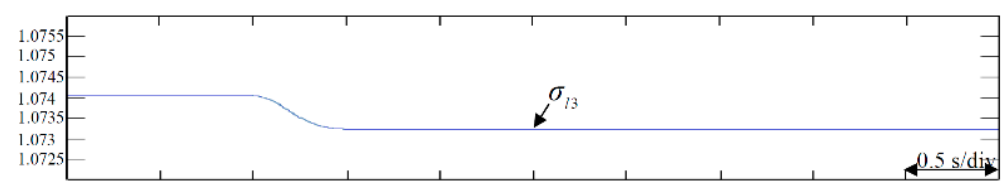

(d)

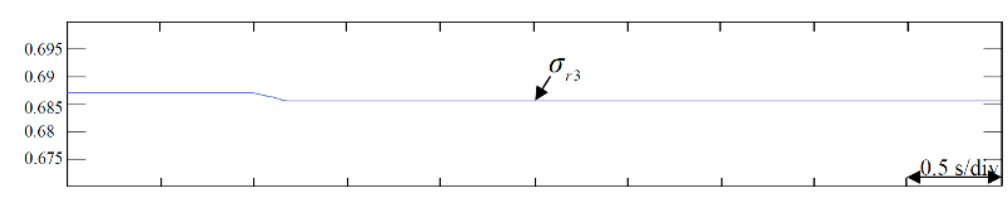

(e)

Figure 8. Responses of network parameters of CFNN-AMF controller at case 1: (a) Responses of $w_{3}$; (b) Responses of $\gamma_{3} ;$ (c) Responses of $m_{3} ;$ (d) Responses of $\sigma_{l 3} ;$ (e) Responses of $\sigma_{r 3}$.

Table 4. Response time of DC-link voltage and regulation voltage error for different controllers at case 2 .

\begin{tabular}{cccc}
\hline \multirow{2}{*}{$\begin{array}{c}\text { Case } \\
\text { Condition }\end{array}$} & $\begin{array}{c}\text { DC-Link } \\
\text { Controllers }\end{array}$ & $\begin{array}{c}\text { Response Time (s) } \\
\text { Linear Inductive Load 1 } \rightarrow \\
\text { Linear Inductive Load 3 }\end{array}$ & $\begin{array}{c}\text { Overshoot to Undershoot (V) } \\
\text { Linear Inductive Load 1 } \rightarrow \\
\text { Linear Inductive Load 3 }\end{array}$ \\
\hline Case 2 & PI & 0.8 & 5 \\
& CFNN & 0.6 & 4 \\
& CFNN-AMF & 0.4 & 3.6 \\
\hline
\end{tabular}




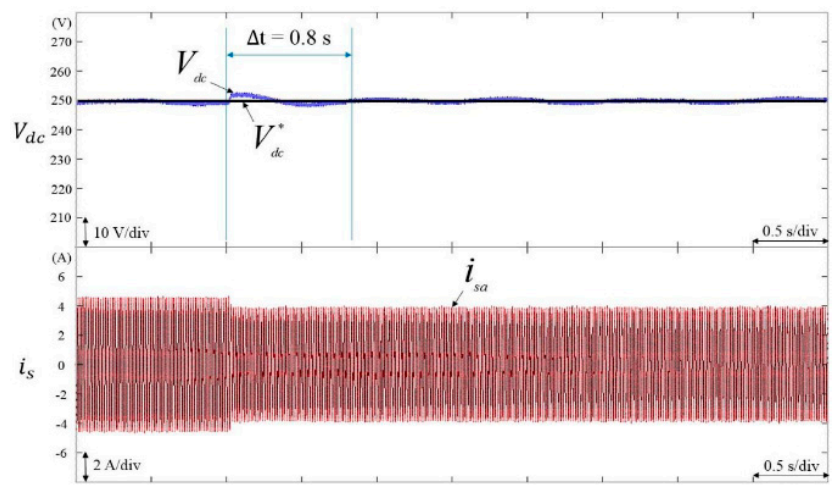

(a)

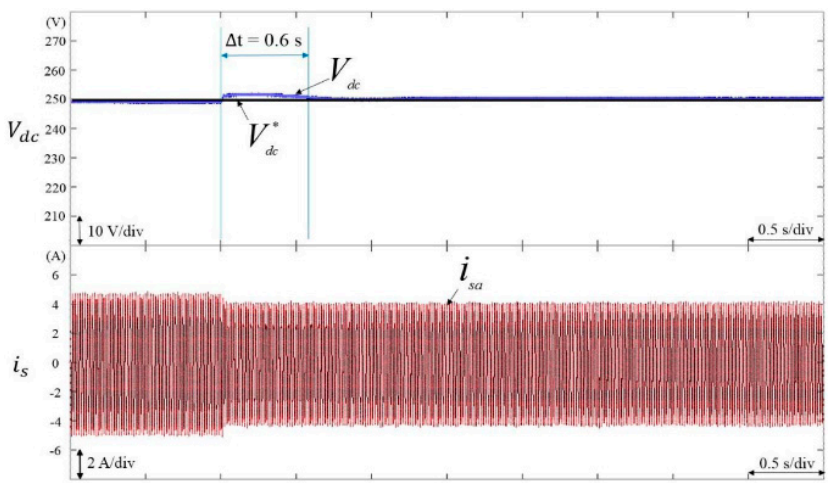

(b)

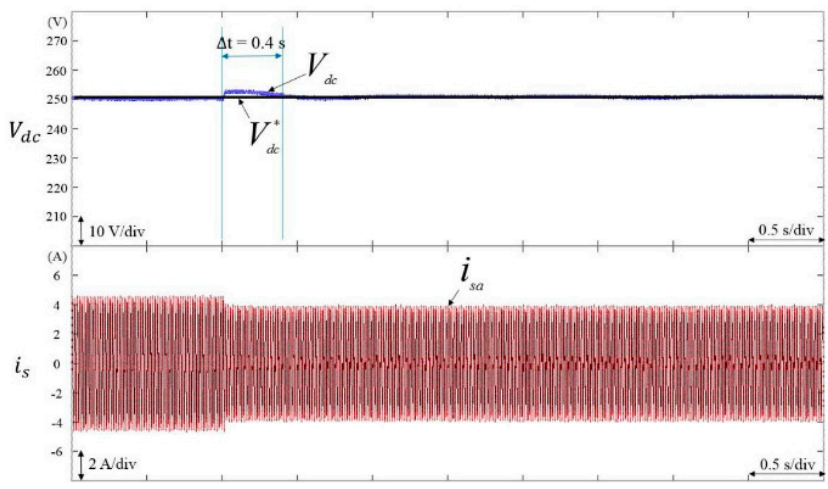

(c)

Figure 9. Experimental results at case 2: (a) Responses of DC-link voltage $V_{d c}$ and grid current $i_{s a}$ using PI controlled DSTATCOM; (b) Responses of DC-link voltage $V_{d c}$ and grid current $i_{s a}$ using CFNN controlled DSTATCOM; (c) Responses of DC-link voltage $V_{d c}$ and grid current $i_{s a}$ using proposed CFNN-AMF controlled DSTATCOM.

\section{Conclusions}

In this study, a DSTATCOM has been proposed to improve the THD of the grid current and PF under the nonlinear and linear inductive loads. In order to improve the power quality and DC-link voltage regulation control of the DSTATCOM under the variation of nonlinear and linear inductive loads, an online trained CFNN-AMF has been proposed as a regulation controller to replace the traditional PI controller in the DSTATCOM. From the experimental results and tables, the current THD, PF and response time of DC-link voltage of the PI controlled DSTATCOM are 4.54\%, 0.996 and $2 \mathrm{~s}$ at the nonlinear load 3, linear inductive load 3 and case 1 . However, due to the online learning capacity and the optimized fuzzy rules of the proposed CFNN-AMF controller, the current THD, PF and response 
time of DC-link voltage of the proposed CFNN-AMF controlled DSTATCOM are 4.17\%, 0.998 and $1 \mathrm{~s}$ at the nonlinear load 3, linear inductive load 3 and case 1 . Therefore, the proposed CFNN-AMF controlled DSTATCOM possesses improved power quality compensation, DC-link voltage regulation control and the quickest response time owing to the powerful robust ability of the proposed CFNN-AMF controller. The major contributions of this study are: (i) the successful development of a DSTATCOM based on $p q$ theory; (ii) the successful development of the online trained CFNN-AMF controller; (iii) the successful integration of the proposed CFNN-AMF controller with the DSTATCOM for power quality improvement and DC-link voltage regulation control.

Author Contributions: K.-H.T. and F.-J.L. designed and developed the main parts of the research work, including theory derivation and analyses of the obtained results. K.-H.T. and F.-J.L. were also mainly responsible for preparing the paper. C.-Y.T. and Y.-R.C. contributed in PC-based control platform, and writing parts.

Funding: The authors appreciate the financial support of the Institute of Nuclear Energy Research of Taiwan, through its grant 107A010.

Conflicts of Interest: The authors declare no conflicts of interest.

\section{References}

1. Mishra, S.; Ray, P.K. Power quality improvement using photovoltaic fed DSTATCOM based on JAYA optimization. IEEE Trans. Sustain. Energy 2016, 7, 1672-1680. [CrossRef]

2. Sekhar, V.C.; Kant, K.; Singh, B. DSTATCOM supported induction generator for improving power quality. IET Renew. Power Gener. 2016, 10, 495-503. [CrossRef]

3. Srinivas, M.; Hussain, I.; Singh, B. Combined LMS-LMF-based control algorithm of DSTATCOM for power quality enhancement in distribution system. IEEE Trans. Ind. Electron. 2016, 63, 4160-4168. [CrossRef]

4. Chittora, P.; Singh, A.; Singh, M. Performance evaluation of digital filters in distribution static compensator for non-linear loads. IET Power Electron. 2017, 10, 1915-1923. [CrossRef]

5. Tan, K.H.; Lin, F.J.; Chen, J.H. Three-phase four-leg inverter-based APF for unbalanced current compensation using PPFNN. Energies 2017, 10, 2005. [CrossRef]

6. Latran, M.B.; Teke, A.; Yoldaş, Y. Mitigation of power quality problems using distribution static synchronous compensator: A comprehensive review. IET Power Electron. 2015, 8, 1312-1328. [CrossRef]

7. Elnady, A.; Salama, M.M.A. Unified approach for mitigating voltage sag and voltage flicker using the DSTATCOM. IEEE Trans. Power Deliv. 2005, 20, 992-1000. [CrossRef]

8. Singh, B.; Arya, S.R.; Jain, C. Simple peak detection control algorithm of distribution static compensator for power quality improvement. IET Power Electron. 2014, 7, 1736-1746. [CrossRef]

9. Venkatraman, K.; Selvan, M.P.; Moorthi, S. Predictive current control of distribution static compensator for load compensation in distribution system. IET Gener. Transm. Distrib. 2016, 10, 2410-2423. [CrossRef]

10. Singh, B.; Solanki, J. A comparison of control algorithms for DSTATCOM. IEEE Trans. Ind. Electron. 2009, 56, 2738-2745. [CrossRef]

11. Kumar, A.P.; Mangaraj, M. DSTATCOM employing hybrid neural network control technique for power quality improvement. IET Power Electron. 2017, 10, 480-489. [CrossRef]

12. Biricik, S.; Redif, S.; Ozerdem, Ö.C.; Khadem, S.K.; Basu, M. Real-time control of shunt active power filter under distorted grid voltage and unbalanced load condition using self-tuning filter. IET Power Electron. 2014, 7, 1895-1905. [CrossRef]

13. Acuña, P.; Morán, L.; Rivera, M.; Dixon, J.; Rodriguez, J. Improved active power filter performance for renewable power generation systems. IEEE Trans. Power Electron. 2014, 29, 687-694. [CrossRef]

14. Arya, S.R.; Singh, B.; Niwas, R.; Chandra, A.; Al-Haddad, K. Power quality enhancement using DSTATCOM in distributed power generation system. IEEE Trans. Ind. Appl. 2016, 52, 5203-5212. [CrossRef]

15. Pandey, R.; Tripathi, R.N.; Hanamoto, T. Comprehensive analysis of LCL filter interfaced cascaded H-bridge multilevel inverter-based DSTATCOM. Energies 2017, 10, 346. [CrossRef]

16. Roncero-Sánchez, P.; Acha, E. Design of a control scheme for distribution static synchronous compensators with power-quality improvement capability. Energies 2014, 7, 2476-2497. [CrossRef] 
17. Somsai, K.; Kulworawanichpong, T. Instantaneous power control of D-STATCOM with consideration of power factor correction. In Proceedings of the 2010 ECTI International Confernce on Electrical Engineering/Electronics, Computer, Telecommunications and Information Technology, Chiang Mai, Thailand, 19-25 May 2010; pp. 1186-1190.

18. Zhang, Y.Q.; Kandel, A. Compensatory neurofuzzy systems with fast learning algorithm. IEEE Trans. Neural Netw. 1998, 9, 83-105. [CrossRef] [PubMed]

19. Seker, H.; Evans, D.H.; Aydin, N.; Yazgan, E. Compensatory fuzzy neural networks-based intelligent detection of abnormal neonatal cerebral Doppler ultrasound waveforms. IEEE Trans. Inf. Technol. Biomed. 2001, 5, 187-194. [CrossRef] [PubMed]

20. Lin, C.H.; Chen, C.H. Identification and prediction using recurrent compensatory neuro-fuzzy systems. Fuzzy Sets Syst. 2005, 150, 307-330. [CrossRef]

21. Lin, F.J.; Hung, Y.C.; Tsai, M.T. Fault-tolerant control for six-phase PMSM drive system via intelligent complementary sliding-mode control using TSKFNN-AMF. IEEE Trans. Ind. Electron. 2013, 60, 5747-5762. [CrossRef]

22. Lin, F.J.; Lu, K.C.; Ke, T.H.; Yang, B.H.; Chang, Y.R. Reactive power control of three-phase grid-connected PV System during grid faults using Takagi-Sugeno-Kang probabilistic fuzzy neural network control. IEEE Trans. Ind. Electron. 2015, 62, 5516-5528. [CrossRef]

23. Ouyang, C.S.; Lee, S.J. An improved learning algorithm for rule refinement in neuro-fuzzy modeling. In Proceedings of the 1999 Third International Conference on Knowledge-Based Intelligent Information Engineering Systems. Proceedings (Cat. No. 99TH8410), Adelaide, Australia, 31 August-1 September 1999; pp. 238-241.

24. Institute of Electrical and Electronics Engineers (IEEE). IEEE Recommended Practice and Requirements for Harmonic Control in Electric Power Systems; IEEE: Piscataway, NJ, USA, 2014.

(C) 2018 by the authors. Licensee MDPI, Basel, Switzerland. This article is an open access article distributed under the terms and conditions of the Creative Commons Attribution (CC BY) license (http:/ / creativecommons.org/licenses/by/4.0/). 